\title{
Microsurgical Resection of Tuberculum Sellae Meningioma through Pterional Approach with Extradural Optic Canal Unroofing
}

\author{
Satoshi Matsuo ${ }^{1}$ Toshiyuki Amano $^{1}$ Sojiro Yamashita ${ }^{1}$ Yuichiro Miyamatsu ${ }^{1}$ Akira Nakamizo ${ }^{1}$ \\ ${ }^{1}$ Department of Neurosurgery, Clinical Research Institute, National \\ Hospital Organization Kyushu Medical Center, Chuo-ku, Fukuoka, \\ Japan \\ Address for correspondence Satoshi Matsuo, MD, PhD, Department \\ of Neurosurgery, Clinical Research Institute, National Hospital \\ Organization Kyushu Medical Center, 1-8-1 Jigyohama, Chuo-ku, \\ Fukuoka, 810-8563, Japan (e-mail: smatsuo1979@gmail.com).
}

J Neurol Surg B Skull Base 2022;83(suppl S3):e635-e636.

\begin{abstract}
Keywords

- optic canal unroofing

- pterional approach

- tuberculum sellae meningioma

- skull base

Tuberculum sellae meningiomas pose significant challenges because they are surrounded by crucial neurovascular structures, such as the optic and oculomotor nerves, pituitary stalk, internal carotid artery and its branches, and the anterior cerebral arteries. Even if small, such meningiomas frequently extend to the optic canal that is considered a poor prognostic factor for vision. In this video clip, we illustrate the case of a 60 -year-old female who had an approximately $3-\mathrm{cm}$ tuberculum sellae meningioma with optic canal involvement. She underwent surgical resection of the tumor through a pterional approach. After extradural optic canal unroofing, detaching, devascularizing, and debulking the tumor, careful dissection of the meningioma from the surrounding tissues was performed. Next, the tumor extensions into both of the optic canals were removed. Finally, coagulation and resection of the tumor origin on the dura of the tuberculum sellae following Simpson's grade-I resection were performed. Histopathology revealed that the tumor was a World Health Organization (WHO) grade-I meningioma. The patient had an uneventful postoperative course and her visual acuity was preserved, with no visual field defect on postoperative visual examination. In this video, the basic surgical techniques in performing extradural optic canal unroofing, preserving the arachnoid plane, and stay in collect layer, which is the essential technique for dissecting meningiomas and for preserving neurovascular structures, are demonstrated.

The link to the video can be found at: https://youtu.be/vD54lji0C4Q.
\end{abstract}

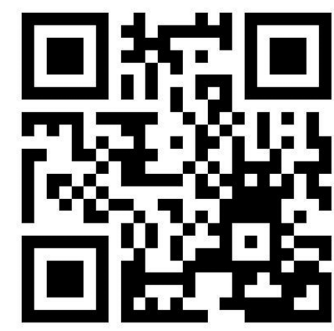

received

April 22, 2020

accepted

December 1, 2020

published online

May 3, 2021

Conflict of Interest

None declared.

www.thieme.com/skullbasevideos

www.thieme.com/jnlsbvideos

DOI https://doi.org/ 10.1055/s-0041-1727148. ISSN 2193-6331. (c) 2021. The Author(s).

This is an open access article published by Thieme under the terms of the Creative Commons Attribution-NonDerivative-NonCommercial-License, permitting copying and reproduction so long as the original work is given appropriate credit. Contents may not be used for commercial purposes, or adapted, remixed, transformed or built upon. (https://creativecommons.org/ licenses/by-nc-nd/4.0/)

Georg Thieme Verlag KG, Rüdigerstraße 14, 70469 Stuttgart, Germany 

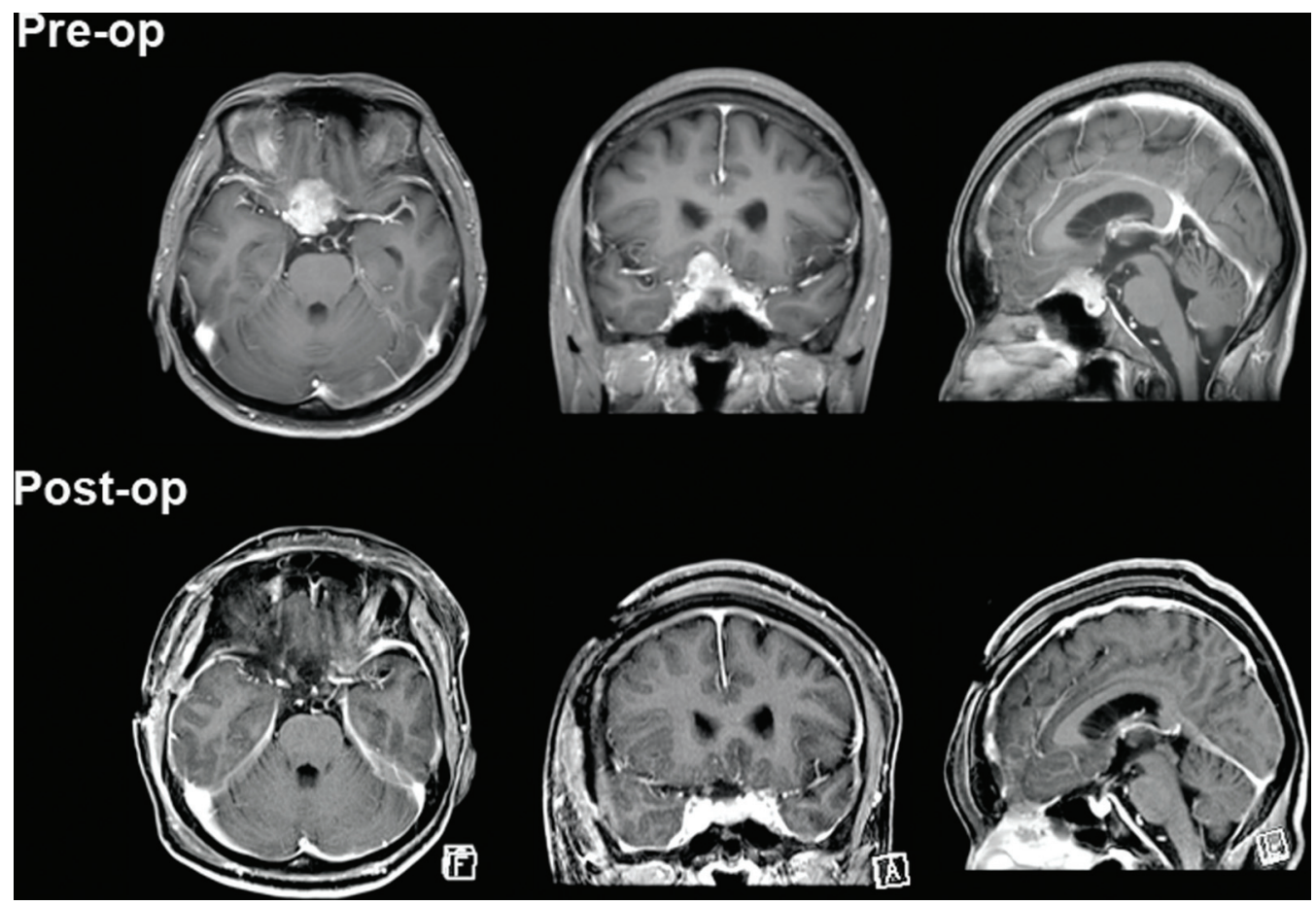

Fig. 1 Pre- and postoperative gadolinium-enhanced T1 weighted images. Gross total resection of the tumor was achieved. Pre-op, preoperative; Post-op, postoperative.

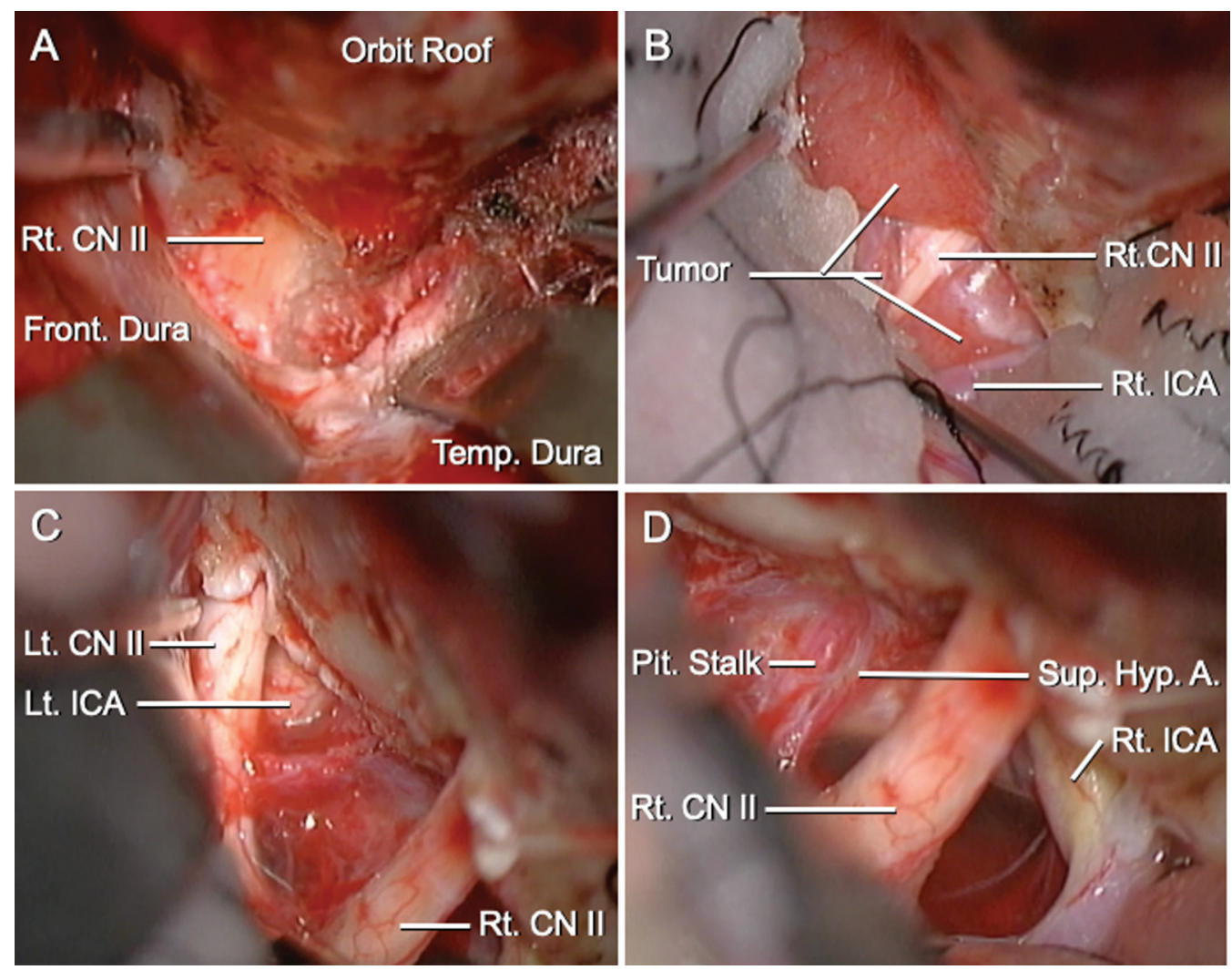

Fig. 2 Intraoperative images of the resection of the tuberculum sellae meningioma through right pterional approach with extradural optic canal unroofing. (A) Extradural optic canal unroofing was performed. The intracanalicular part of the optic nerve was exposed. (B) The right optic nerve was encased by the tumor and pushed upward. (C and D) Simpson's grade 1 resection was achieved. A., artery; CN, cranial nerve; Front., frontal; Hyp., hypopheseal; ICA, internal carotid artery; Lt., left; Pit., pituitary; Rt., right; Sup., superior; Temp., temporal. 